\title{
A STUDY OF THE FECUNDITY OF SOME MORM M̈YID FISHES FROM LAKE VICTORIA
}

\section{J. Okedi, East African Freshwater Fisheries Research Organization, Jinja, Uganda \\ (Received for publication on 10th February 1969)}

The need for a rational exploitation of the fish stocks in the Lake Victoria Basin has, during recent years, necessitated further investigation of the breeding potential of the species of commercial importance. Because of their greater commercial importance in East Africa, the fecundity of species belonging to the families Cichlidae and Cyprinidae is better known than that of the Mormyridae. Lowe (1955) has described the breeding potential of a number of Tilapia and Cadwalladr (1965) has published some notes on fecundity in the cyprinid fish, Labeo victorianus Boulenger. The only available reference to fecundity in the Mormyridae, is that of Nawar (1959b), who made some observations on Hyperopisus bebe Lacepede from the Nile. Although members of the Mormyridae at present make up a relatively small part of the total landings of fish from Lake Victoria, the group is nevertheless becoming one of increasing commercial importance to the fishery of the affluent rivers, Okedi (1966).

For the purpose of this study, fecundity is defined as the number of eggs contained in the ovary. This definition has been used by Nikolsky (1963), Allee et al. (1949) and Dice (1952). Lowe (1955) has, however, defined it as the number of young produced during the lifetime of an individual.

\section{Methods}

Fish were obtained from a wide range of habitats. Mormyrus kannume was caught in deep waters with rocky bottoms, and the other species from the littoral areas of Lake Victoria and affluent rivers. Several methods were employed in catching the fish, including gill-nets seine-nets and local basket-traps.

After taking standard lengths and weights of fish, the ovaries were removed and weighed fresh. Only the ovaries from ripe and running females were used for egg counting and these wero preserved in 6 per cent formaldehyde solution until required for use.

The diameter of the ova was measured with a binocular microscope at a magnification of $x 7.25$ and several different oocytes and ova were measured for each ovary. After preservation in formaldehyde solution, some large ova appeared deformed, but these were neglected during measurement.

The ovary

\section{Results}

In the Mormyridae, generally only one gonad is developed (Greenwood, 1966). However, one female Mormyrus kannume (S.L. $22.6 \mathrm{~cm}$., body weight $170 \mathrm{gm}$.) caught by the author on 27th September 1966 had two ovaries completely developed to sexual maturity (Fig. 1). The ovaries were typically ventral to the swim bladder, with the stomach in an anterior position. The two ovarian ducts were well developed and led separately into the genital aperture.

In the six species studied, the shape and colour of the ovary depended on its state of sexual maturity. The young ovary is a small translucent body lodged between the swim bladder and the abdominal wall. It assumes first a triangular outline and then becomes rhomboidal as it grows larger. Its colour changes to white-grey as oocytes accumulate yolky deposits. The ovary thereafter tends to be drawn out in an antero-posterior direction to become oval as it ripens. In a gravid fish, the single ovary completely fills the abdominal cavity, subjecting the internal viscera to pressure, and itself taking on the oval shape of the abdominal cavity. The abdominal walls are extremely distended and the stomach is frequently compressed to become a small hard ball. In many cases only a little food was found in the stomach of fully ripe females. The colour of the ovary changes from whitegrey when ripe to golden yellow when running. and becomes dirty brown when spent. In all the species examined, the fully developed ovary formed less than 25 per cent of the total body weight.

\section{The histology of the ovary}

Selected ovaries were fixed with Smith's formol bichromate solution, embedded in paraffin wax and sectioned with a microtome at 


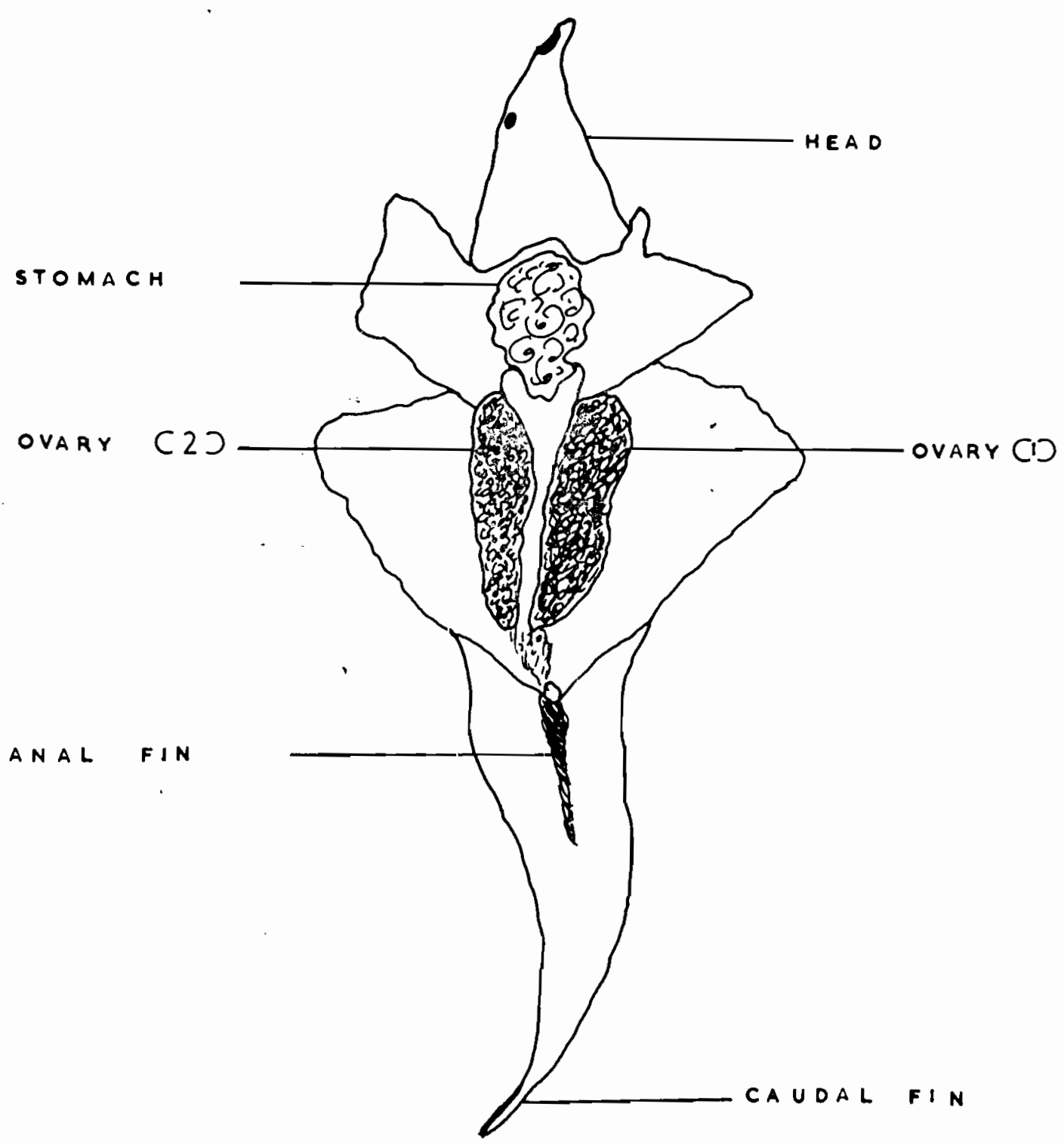

Fig. 1-Ventral dissection of a specimen of Mormyrus kannume illustrating the position in the abdominal cavity of the two well-developed ovaries

0.008-0.01 $\mathrm{mm}$. The sections were later stained using azocarmine, cleared in aniline alcohol, mounted in Canada Balsam and microscopically examined at $\times 17$ magnification.

The general characteristics of the oocytes and ova in the mormyrids examined were similar. Primary oocytes measured between $0.059-0.088 \mathrm{~mm}$. in diameter and occurred clustered together, with all the cells ioined by thin intercellular walls. The large central nuclei stained bluish grey and the surrounding cytoplasm stained blue. Immature ovaries were characterized by the predominance of primary oocytes, although these also occurred, but fewer in numbers, in ovaries which were ripening.

In ripening ovaries, there was a mixture of primary and secondary oocytes, with the latter 
predominating. The secondary oocytes appeared larger, $0.090-0.350 \mathrm{~mm}$. in diameter. The smaller of these cells contained tiny bodies which stained purplish red and occurred amongst the blue staining cytoplasm. Other bodies, staining yellowish red, appeared as inclusions amongst the purplish-red bodies. It was assumed that the purplish-red bodies were yolk precursors, because in slightly larger secondary oocytes the yolk inclusions were more numerous, whereas the precursors remained relatively few.

Ripe ovaries contained predominantly mature ova whose numerous yolk inclusions stained bright yellowish-red. Released ova were seen lying free in the ovarian lumen. In partly spawned ovaries, empty follicles were characteristic. It was noted, however, that in both ripe and partly spawned ovaries, small oocytes, mostly in their primary stage of development, occurred along the periphery of the ovary and distinct from the germinal layer. Some secondary oocytes also appeared between the primary oocytes and developed ova. Table I shows the sizes of the ova of the mormyrid species studied. Variability of ova size is negligible in all the species as indicated aby the very low magnitude of the standard error of the mean diameters: ranging between \pm 0.007 to \pm 0.025 . It seemed, however, that in the species studied, egg size is not affected by the standard length of the fish. Marcusenius nigricans, one of the smallest and least fecund species, has the largest eggs. Mormyrid eggs are larger than those of the cyprinid, Labeo victorianus (mean diameter $0.65 \mathrm{~mm}$.) (Cadwalladr, 1965), but smaller than those of the Tilapia species studied by Lowe (1955), which have mean diameters between $2-5 \mathrm{~mm}$. The production of small numbers of yolky ova in contrast to the production of large numbers of yolk-free ova is usually related to some degree of parental care (Nikolsky, 1963). Although the Mormyrids may display parental care of their progeny (Okedi, 1968), this behaviour has not yet been observed.

Table I-The Sizes of the Ova of Six Mormyrid Species

\begin{tabular}{|c|c|c|c|c|c|c|c|}
\hline & & & \multirow{2}{*}{$\begin{array}{l}\text { No. of fish } \\
\text { examined }\end{array}$} & \multirow{2}{*}{$\begin{array}{c}\text { Standard } \\
\text { Length } \\
\text { Range }(\mathrm{cm} .)\end{array}$} & \multicolumn{2}{|c|}{ Ova Diameter (mm.) } & \multirow{2}{*}{ S.E. $\pm^{*}$} \\
\hline & & & & & Range & Mean & \\
\hline $\begin{array}{l}\text { Mormyrus kannume } \\
\text { Gnathonemus victoriae } \\
\text { G. longibarbis } \\
\text { Marcusenius grahami } \\
\text { M. nigricans.. . } \\
\text { Petrocephalus catostoma }\end{array}$ & $\begin{array}{l}\cdots \\
\cdots \\
\cdots \\
\cdots \\
\cdots\end{array}$ & \begin{tabular}{l|}
$\cdots$ \\
$\cdots$ \\
$\cdots$ \\
$\cdots$ \\
$\cdots$ \\
$\cdots$
\end{tabular} & $\begin{array}{r}132 \\
44 \\
68 \\
91 \\
71 \\
81\end{array}$ & $\begin{array}{r}18 \cdot 3-37 \cdot 7 \\
11 \cdot 7-19 \cdot 1 \\
9 \cdot 5-18 \cdot 8 \\
7 \cdot 5-13 \cdot 7 \\
7 \cdot 0-9 \cdot 1 \\
5 \cdot 1-7 \cdot 3\end{array}$ & $\begin{array}{l}1 \cdot 8-2 \cdot 5 \\
1 \cdot 5-1 \cdot 9 \\
1 \cdot 3-1 \cdot 8 \\
1 \cdot 3-1 \cdot 8 \\
2 \cdot 1-2 \cdot 9 \\
1 \cdot 4-1 \cdot 8\end{array}$ & $\begin{array}{l}2 \cdot 14 \\
1 \cdot 63 \\
1 \cdot 60 \\
1 \cdot 52 \\
2 \cdot 38 \\
1 \cdot 57\end{array}$ & $\begin{array}{l}0 \cdot 014 \\
0 \cdot 007 \\
0 \cdot 012 \\
0 \cdot 014 \\
0.025 \\
0.012\end{array}$ \\
\hline
\end{tabular}

*S.E. $=$ Standard error of the mean

\section{Fecundity}

The data in Table II illustrate the general aspects of the fecundity of six mormyrid species from the Lake Victoria Basin and show that the species do not produce a great many eggs. This table further indicates the standard error of the means of fecundity for each species. In the smallest species, Marcusenius nigricans and Petrocephalus catostoma, which also happen to be the least fecund, the standard error of the means are very low $( \pm 18$ and \pm 25 respectively) showing that the means of these samples very closely approximate the true mean of whole populations. In the remaining species, the standard error of the mean fecundity range from \pm 224 to \pm 507 . These figures may seem high but when viewed in regard to the large magnitude of the observed means themselves 2,177 to 6,869 , the standard errors will appear reasonable. The means of the samples therefore give a rational estimation of the true means in natural populations taking into account the variability of egg counts depending on factors such as length, age, etc. Further, the lower length range in Table II gives an indication of the length of the smallest ripe specimen caught, and demonstrates the size of female fish at the attainment of sexual maturity for each species. The single exception is Marcusenius nigricans, where $7.0 \mathrm{~cm}$. is well above the expected size of the smallest ripe fish. 
Table II--Summarized Results on the Fecundity of The Mormyridae

\begin{tabular}{l|c|r|r|r|r|r}
\hline \multicolumn{1}{c|}{ Species } & $\begin{array}{c}\text { No. of } \\
\text { Specimens } \\
\text { examined }\end{array}$ & $\begin{array}{c}\text { Range } \\
\text { Standard } \\
\text { Length } \\
\text { (cms.) }\end{array}$ & $\begin{array}{c}\text { Range } \\
\text { Body-Weight } \\
\text { (gms.) }\end{array}$ & $\begin{array}{c}\text { Range } \\
\text { Fecundity }\end{array}$ & $\begin{array}{c}\text { Mean } \\
\text { Fecundity }\end{array}$ & S.E.土* \\
\hline Mormyrus kannume .. & 66 & $18 \cdot 3-37 \cdot 7$ & $75 \cdot 6-643 \cdot 2$ & $1,393-17,369$ & 6,869 & 421 \\
Gnathonemus victoriae & 92 & $11 \cdot 7-19 \cdot 1$ & $14 \cdot 7-163 \cdot 2$ & $846-16,748$ & 6,363 & 317 \\
G. longibarbis .... & 38 & $9 \cdot 5-18 \cdot 8$ & $11 \cdot 0-118 \cdot 5$ & $502-14,624$ & 4,688 & 507 \\
Marcusenius grahami... & 32 & $7 \cdot 5-13 \cdot 7$ & $9 \cdot 2-57 \cdot 8$ & $248-5,229$ & 2,177 & 224 \\
M. nigricans ..... & 58 & $7 \cdot 0-9 \cdot 1$ & $7 \cdot 3-13 \cdot 0$ & $206-739$ & 408 & 18 \\
Petrocephalus catostoma & 66 & $5 \cdot 1-7 \cdot 3$ & $5 \cdot 5-8 \cdot 5$ & $116-1,015$ & 557 & 25 \\
\hline
\end{tabular}

$*$ S.E. $=$ Standard error of the mean.

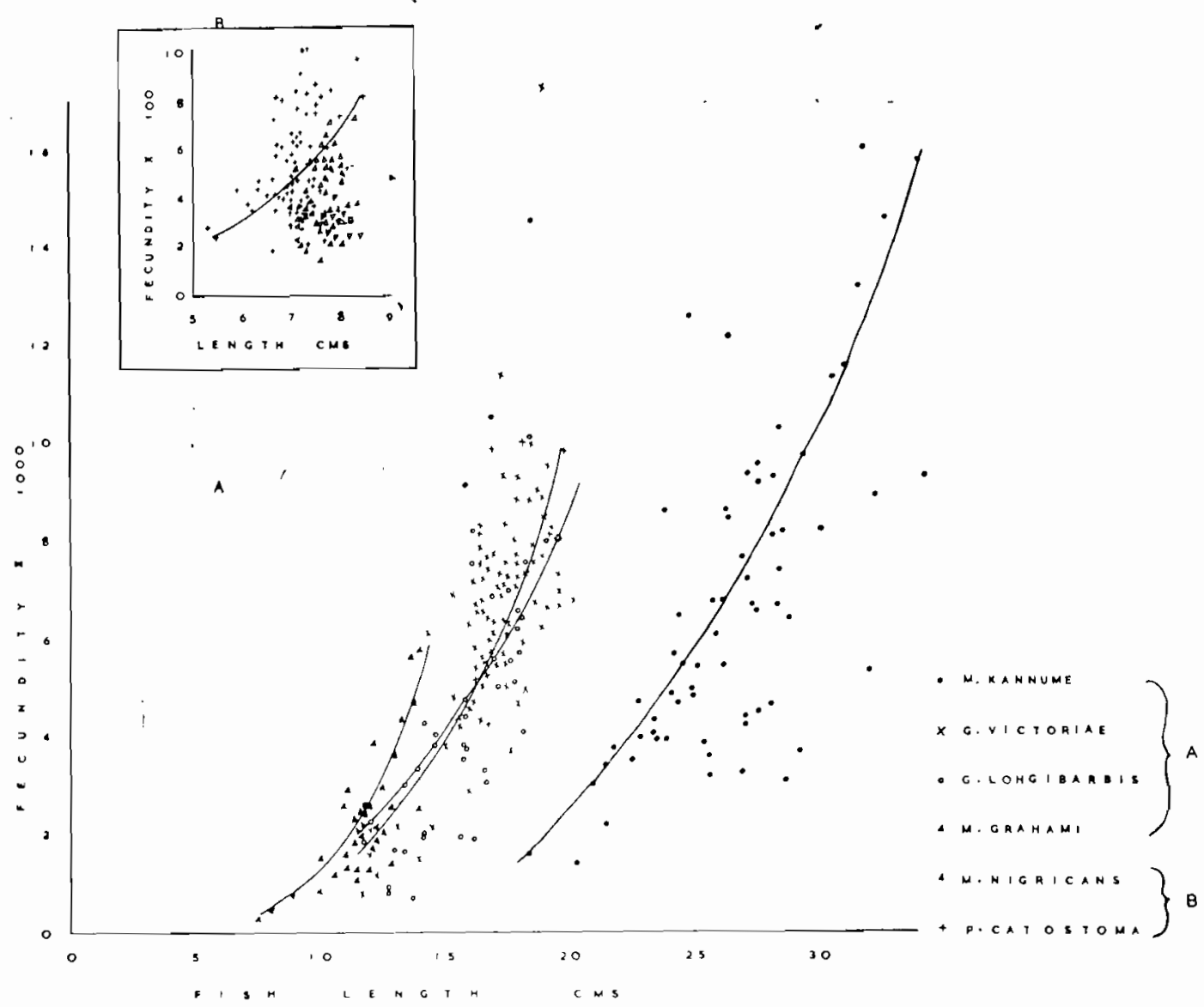

Fig. 2-Fecundity estimates of six mormyrid species by standard length together with the fitted regression lines for five species 
Relationship between fecundity and standard length

Figure II shows fecundity plotted against standard length in each of the six mormyrid species studied. The scatter of points suggest a curvilinear relationship and the relation between fecundity and length can, therefore, be represented as follows:-

$$
\text { where } \begin{aligned}
& \mathbf{F}=\mathbf{K L b}=\text { Fecundity } \\
& \mathbf{K}=\text { Regression constant } \\
& \mathbf{L}=\text { Standard legnth of fish } \\
& \mathbf{b}=\text { Regression coefficient }
\end{aligned}
$$

The above formula may be transformed into its logarithmic form:-

\section{Log Fecundity $=\log . \mathrm{K}+\mathrm{b} \log$ length}

This represents the general curve of the regression line.
The regressicn coefficient $b$, is calculated from the formula :-

$$
b=\frac{\Sigma x y}{\Sigma x^{2}}
$$

where $\Sigma x y=$ the sum of the products of the deviations of $x$ and $y$

$\Sigma x^{2}=$ the sum of the squares of the deviations of $\mathbf{x}$.

The fitted regression lines in Fig. II are described by the following logarithmic equations :-
M. kannume $\quad: \quad \mathrm{F}=3.6800 \mathrm{~L}-1.3927$
G. victoriae : $\mathrm{F}=3.1295 \mathrm{~L}-0.0788$
G. longibarbis : $\quad F=2.7967 \mathrm{~L}-0.3220$
G. grahami : $F=3.1986 \mathrm{~L}-0.0479$
$M$. nigricans : $F=1.9280 \mathrm{~L}+0.9147$
P. catostoma $: \quad F=2.8278 \mathrm{~L}+0.3051$

Table III--The Relationship Between Log Fecundity and Log Standard LenGth of Six Mormyrid Species

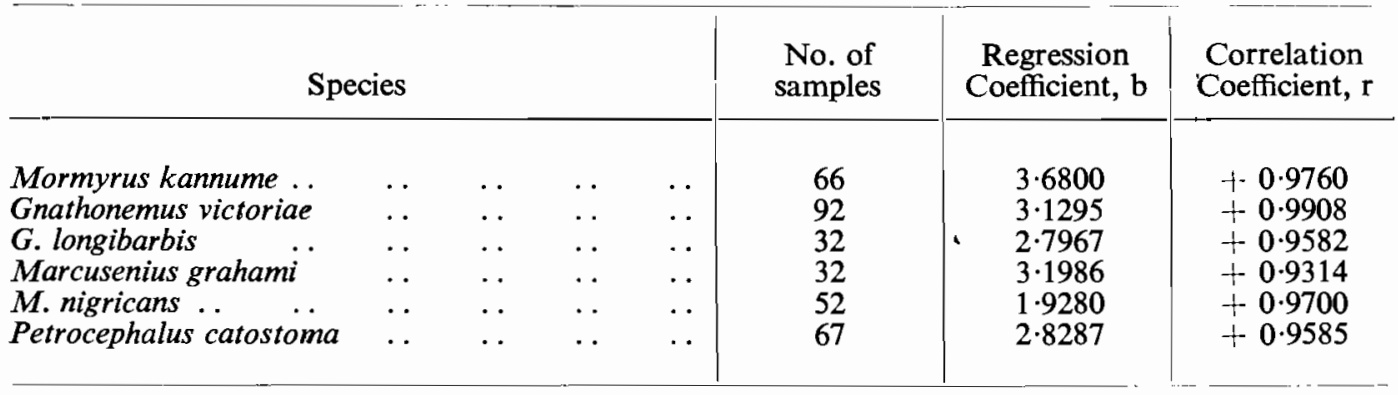

Fecundity, therefore, tends to increase with length and this is supported by the high correlation coefficient $r$ given in Table III.

Further, the regression coefficient $b$, shown in Table III represents the relative increase of fecundity with length. For all the species except $M$. nigricans, fecundity increases at a rate close to the cube of the length. In the mouth brooding cichlid fish, Tilapia leucosticta, Welcomme (1967) has shown that egg production increases approximately as the square of the total length and using Lowe's (1955) figures, he concluded that the cubic relationship between egg production and length was obtainable in the guarder species, Tilapia zillii.

\section{Relation between fecundity and weight}

Fecundity tends to increase with body weight of fish as indicated by the correlation coefficient $r$ in Table IV. In two species, $M$. grahami and $M$. nigricans, the correlation coefficient $r$ is lower than in the other species. The relative rate of increase of fecundity with weight is given by the regression coefficient $b$ in Table IV. In all species except $M$. nigricans the relative increase of fecundity with weight is approximately unity, indicating a linear relationship between the two variables.

\section{Discussion}

Various authors have used the word fecundity to convey different meanings. Lowe (1955) has used it to mean the number of young produced during the lifetime of an individual. More commonly, however, fecundity has been described as the number of eggs contained in the ovary (Nikolsky, 1963) and this agrees with the earlier description of the word fecundity by Allee et al. (1949) and Dice (1952). Similarly, Welcomme (1967) described the fecundity of Tilapia leucosticta 
Table IV-The Relationship Between Log Fecundity and Log Body WeIGHT In Srx MoRmyrid SPECIES

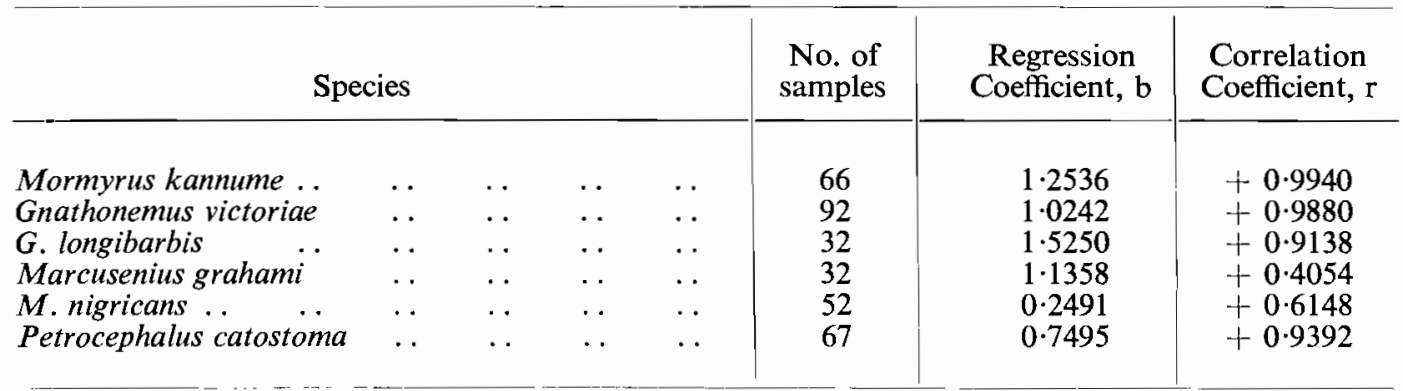

in relation to egg production. In this study, fecundity has been applied to define the number of eggs contained in the ovary over a single breeding season. In this context, fecundity is distinctly differentiated from fertility which according to Allee et al. (1949), Nikolsky (1963) and Welcomme (1967) relates to the number of eggs that successfully develop into living young. In the mormyrid species under study, there was no indication of what proportion of eggs were successfully fertilized.

On the whole, the mormyridae are not very fecund. Mormyrus kannume, the largest species was the most fecund whereas Marcusenius nigricans and Petrocephalus catostoma, the smallest species were shown to produce the fewest number of eggs. Although $M$. nigricans has a low fecundity, this species tends to breed continuously unlike Gnathonemus victoriae, G. longibarbis, Marcusenius grahami and Petrocephalus catostoma which breed twice yearly (Okedi, 1969). Low fecundity in these species may perhaps be correlated with low mortality rates and high frequency of successfully fertilized ova although there is presently no evidence to show this. However, amongst scattered references, it is indicated that the Nile crocodile (Crocodilus niloticus) feeds heavily on fish (Cott, 1961) and some of these may be members of the mormyridae. The larger cormorant, Phalacrocorax carbo sometimes take Mormyrus kannume (Corbet, 1961). Okedi (1966) has shown that man too is an important predator of the mormyrid fishes particularly in rivers during seasonal spawning migrations.

It is stated for the first time that the fecundity of the species studied, except $M$. nigricans increases at a rate close to the cube of standard length. In the mouth brooding cichlid fish, Tilapia leucosticta, Welcomme (1967) has shown that egg production increases approximately as the square of the total length and using Lowe's (1955) figures he concluded that the cubic relationship between egg production and length was obtainable in the guarder species, Tilapia zillii. The linear relationship between fecundity and body weight in the mormyrids studied is similar to the condition in $T$. leucosticta as reported by Welcomme (1967).

The occurrence of a single specimen of Mormyrus kannume with two well-developed ovaries is indeed a rare instance and from Greenwood's (1966) remarks and personal observations it is noted that the mormyridae normally possess a single gonad. Similarly, amongst the Nile Mormyridae, Nawar (1959a) has noted that only the left gonad is developed; the right one being vestigial.

Secondary oocytes in varying stages of development were frequently seen in fully ripe ovaries. In running fish (ready to spawn) such small oocytes were very few and it would seem that most of these oocytes completed maturation rapidly and are spawned during one breeding season together with the earlier developed ova. In the Nile Mormyrid, Hyperopisus bebe, Nawar $(1959 b)$ has concluded that small oocytes develop quickly and are spawned together with the large ova during one season. In the mormyrids studied, it was observed that towards the end of the breeding season, the ovaries became congested and eventually turned dark brown. In such ovaries oocytes and unshed ova were reduced to chocolate brown granules. It would appear, therefore, that there is resorption of oocytes and ova after peak breeding activity. 


\section{ACKNOWLEDGEMENTS}

The author is indebted to Mr. P. B. N. Jackson and Dr. J. C. D. Watts for useful suggestions and for reading through the manuscript.

\section{REFERENCES}

[1] Allee, W. C., Park, G., Emerson, A. E., Park, T., and Schmidt, K. F. (1949). Principles of Animal Ecology, W. B. Saunders Company, Philadelphia and London.

[2] Cadwalladr, D. A. (1965). Notes on the breeding biology and ecology of Labeo victorianus Boulenger (Pisces:Cydrinidae) of Lake Victoria. Rev. Zool. Bot. Afr., 72, 109-124.

[3] Corbet, P. S. (1961). The food of non-cichlid fishes in Lake Victoria Basin with remarks on their evolution and adaptation to lacustrine conditions. Proc. Zool. Soc. Lond., 136, 1-101.

[4] Cott, H. B. (1961). The scientific results of an enquiry into the ecology and economic status of the Nile Crocodile (Crocodilus niloticus) in Uganda and Northern Rhodesia. Trans. Zool. Soc. Lond., 29, Part 4, 211-356.

[5] Dice, L. R. (1952). Natural communities. Univ. Michigan Press. Ann. Arbor.
[6] Greenwood, P. H. (1966). The fishes of Uganda. 2nd Ed., Uganda Society, Kampala.

[7] Lowe (McConnell), R. H. (1955). The fecundity of Tilapia species. E. Afr. agric. J., 21 (1), 45-52.

[8] Nawar, G. (1959a). Observations on the breeding of six members of the Nile Mormyridae. Ann. Mag. Nat. Hist. (13), 2, 603-606.

[9] - $(1959 \mathrm{~b})$. A study of the fecundity of the Nile mormyrid. Hyperopisus bebe Lacepede. Ann. Mag. Nat. Hist. (13), 2, 493-504.

[10] Nikolsky, G. V. (1963). The Ecology of Fishes. Academic Press, London and New York.

[11] Okedi, J. (1966). Some aspects of the commercial fishery of the Mormyridae with special reference to the smaller species. E.A.F.F.R.O. Ann. Rep. (1965), 49-55.

[12] (1968). Notes on the behaviour of the small mormyrid fishes of Lake Victoria. E.A.F.F.R.O. Ann. Rep., 1967, 42-48.

[13] - (1969). Observations on the breeding and growth of certain mormyrid fishes of the Lake Victoria Basin. Rev. Zool. Bot. Afr., 79, 34-64.

[14] Welcomme, R. L. (1967). The relationship between fecundity and fertility in the mouthbrooding cichlid fish Tilapia leucosticta. J. Zool. Lond., 151, 453-468. 